\title{
Influences of Mo addition on mechanical properties and deformation behavior of $\beta$-type Ti alloys
}

\author{
K. Cho ${ }^{\mathrm{a},{ }^{*}, \text { R. Morioka }}{ }^{\mathrm{a}}$, H.Y. Yasuda ${ }^{\mathrm{a}}$ \\ a Graduate School of Engineering, Osaka University, 2-1, Yamadaoka, Suita, Osaka 565-0871, Japan \\ *k_cho@mat.eng.osaka-u.ac.jp
}

\begin{abstract}
$\underline{\text { Abstract }}$
The influences of Mo addition on the tensile properties and deformation behavior of $\beta$-type Ti-Mn alloys were investigated with particular focus on $\{332\}<113>$ deformation twinning. We found that Ti-7Mn and Ti-5Mo-3Mo alloys exhibit completely different tensile properties, despite having the same microstructure and stability of the $\beta$ phase. The Ti-5Mn-3Mo alloy demonstrates higher tensile strength and larger ductility than the Ti-7Mn alloy due to its strong work hardening, caused by $\{332\}$ $<113>$ deformation twinning. The critical resolved shear stress (CRSS) for $\{332\}<113>$ deformation twinning in these alloys was measured by compression tests using single crystals. It was thereby found that Mo addition is effective in decreasing the CRSS for $\{332\}<113>$ deformation twinning in Ti-Mn alloys.
\end{abstract}

\section{Introduction}

Owing to their high specific strength, good biocompatibility, and corrosion resistance, titanium (Ti) and its alloys find wide use in many biomedical applications that include bone plates, hip joints, and spinal fixation devices [1-4]. However, the mismatch between the Young's modulus $(E)$ of the human bone (10-30 GPa) and that of Ti alloys (110 GPa for Ti-6Al-4V ELI) can cause stress shielding or stress protection which leads to bone resorption [5-7]. In order to overcome this problem, some $\beta$-type Ti alloys were developed as low-Young's modulus alloys. For instance, the Ti-29Nb-13Ta-4.6Zr alloy is characterized by a Young's modulus of approximately $60 \mathrm{GPa}$ [8], an excellent strength-ductility balance [9] and good fatigue properties [10]. However, present $\beta$-type Ti alloys contain high-cost elements such as niobium $(\mathrm{Nb})$ and tantalum $(\mathrm{Ta})$. Therefore, it is necessary to develop new low-cost 
In a previous study, manganese (Mn) was selected as an alloying element owing to its lower cost and lower cytotoxicity compared with other $\beta$-stabilizing elements. Ti-9Mn alloy shows an ultimate tensile strength (UTS) and Young's modulus higher than $1000 \mathrm{MPa}$ and lower than $100 \mathrm{GPa}$ [11], respectively. Moreover, $90 \%$ cold-rolled Ti-13Mn alloy fabricated by metal injection molding exhibits a UTS higher than $1800 \mathrm{MPa}$ [12]. These high strengths of the alloys are due to precipitation hardening caused by the nanosized athermal $\omega$ phase. Nevertheless, the tensile elongation of these alloys is significantly low. Therefore, it is required to improve the ductility of these alloys.

The ductility of $\beta$-type Ti alloys can be improved by promoting $\{332\}<113>$ deformation twinning which is one of the unique deformation modes for $\beta$-type Ti alloys [13]. Tsuchiya et al. [14] and Gloriant et al. [15] studied the mechanical properties and deformation modes of Ti-Mo and Ti-Nb alloys, respectively, focusing on $\{332\}<113>$ deformation twins. These alloys show an elongation to fracture (EL) larger than $20 \%$. As is well known, the mechanical properties and deformation mode of $\beta$-type Ti alloys vary depending on the phase stability of the b matrix which can be controlled by the contents of the alloying element [16]. The effect of Mn content on the deformation mode and mechanical properties of Ti-Mn alloys has been examined in previous studies. It was found that it is difficult to obtain $\{332\}<113>$ twins in these alloys [11]. Thus, it is necessary to design new alloys with improved ductility.

In this study, molybdenum (Mo) was added as a third alloying element to Ti-Mn alloys, because Ti-Mo alloys are known to deform via $\{332\}<113>$ deformation twinning [17]. Moreover, Mo is generally considered to have low toxicity in the human body [18]. The microstructure and mechanical properties of the Ti-Mn-Mo alloys were thereby examined. Moreover, the influences of Mo addition on the deformation behavior of the alloys was investigated using single crystals of the alloys by focusing on the critical resolved shear stress (CRSS) for $\{332\}<113>$ deformation twinning.

\section{Material and experiments}

Ti-7Mn (mass\%) and Ti-5Mn-3Mo ingots were prepared by arc melting using high-purity Ti, Mn, and Mo in an argon (Ar) atmosphere. It should be noted that the valence electron to atom ratio (e/a) which is an index representing the phase stability of the bcc phase is the same for Ti-7Mn and Ti5Mn-3Mo alloys (approximately 4.2). Hereafter, the Ti-7Mn and Ti-5Mn-3Mo alloys are referred to as TM7 and TMM53, respectively. The ingots were subjected to solution treatment for $3.6 \mathrm{ks}$ at $1173 \mathrm{~K}$ in an Ar atmosphere followed by water quenching. In order to obtain single crystals of the alloys, some ingots were subjected to heat treatment for grain coarsening at $1673 \mathrm{~K}$ for $36 \mathrm{ks}$ in a vacuum. 


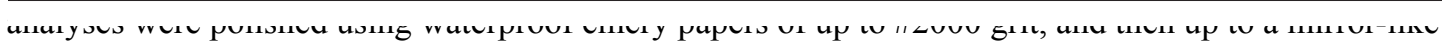
finish using a colloidal $\mathrm{SiO}_{2}$ suspension.

Tensile properties of the alloys were investigated using an Instron-type testing machine with a strain rate of $1.67 \times 10^{-4} \mathrm{~s}^{-1}$ at room temperature in air. Tensile specimens with a gauge dimension of $5.0 \times 1.5 \times 1.0 \mathrm{~mm}$ were obtained from the solutionized alloys using electro-discharge machining. The CRSS for $\{332\}<113>$ deformation twinning was measured by subjecting single crystals of the alloys to a compression test using an Instron-type testing machine at a strain rate of $1.67 \times 10^{-4} \mathrm{~s}^{-1}$ under room temperature in air. Single crystal specimens with dimension of $2.0 \times 2.0 \times 5.0 \mathrm{~mm}$ were prepared from the heat-treated ingots with an average grain diameter larger than $10 \mathrm{~mm}$ using electrodischarge machining. The orientation of the specimens was determined by the Laue back reflection method. To measure the CRSS for $\{332\}<113>$ deformation twinning, the [238] orientation was chosen for the loading axis in the compression test. The Schmid factor for $\{332\}<113>$ twinning at the [238] orientation was 0.49 . All the specimens used for the mechanical tests were mechanically polished as previously described.

The deformation structure of the tensile- and compression-tested specimens was investigated by electron backscatter diffraction (EBSD) and TEM analyses. The fracture surface of the tensile-tested specimens was observed by scanning electron microscopy (SEM).

\section{Results}

\subsection{Microstructure}

Fig. 1 and Fig. 2 show the XRD profiles and OM images, respectively, of polycrystalline TM7 and TMM53. Only diffraction peaks for the $b$ phase can be observed in the XRD profiles. These results indicate that the equiaxed grains shown in Fig. 2 are composed of the b phase. Moreover, TEM analyses indicates that the nanosized athermal $\omega$ phase is dispersed uniformly in these alloys (data not shown here). The values of 0002 to 222 reciprocal lattice vector ratios $\left(d^{*}{ }_{0002} / d^{*}{ }_{222}\right)$ [19] as calculated by the selected area electron diffraction patterns are 0.662 for both TM7 and TMM53. This indicates that the b matrixes of both TM7 and TMM53 have similar phase stability. 


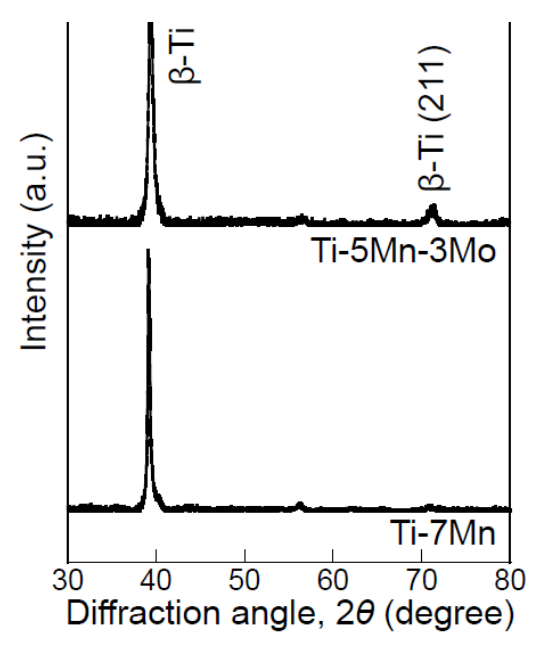

Fig. 1 XRD profiles of TM7 and TMM53.

(a)

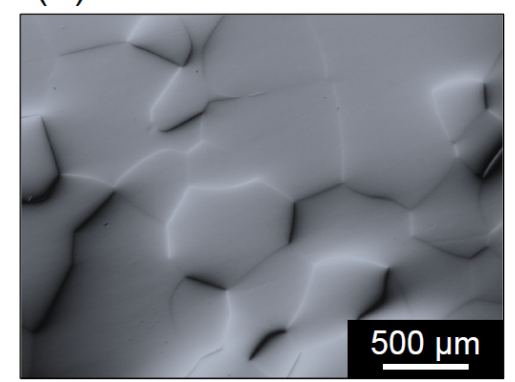

(b)

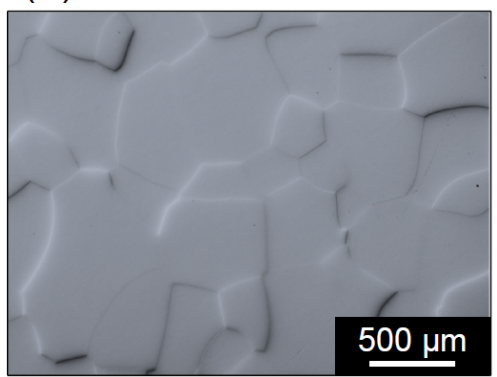

Fig. 2 Typical OM images of TM7 (a) and TMM53 (b).

\subsection{Mechanical properties}

The tensile properties of TM7 and TMM53 are listed in Table 1. The UTS of TMM53 is higher than that of TM7 while the yield stress (YS) of TMM53 is almost the same as that of TM7. Moreover, 
Table 1 Tensile properties for TM7 and TMM53.

\begin{tabular}{cccc}
\hline & YS (MPa) & UTS (MPa) & EL (\%) \\
\hline Ti-7Mn & 813 & 828 & 6.0 \\
Ti-5Mn-3Mo & 811 & 939 & 32.5 \\
\hline
\end{tabular}

SEM fractographs of the tensile deformed specimens for the studied alloys are shown in Fig. 3. There are numerous dimples on the fracture surface in both alloys, indicating that their fracture mode is ductile fracture. The deformation behavior of the alloys was investigated by OM and SEM analyses of the surfaces of TM7 and TMM53 tensile deformed to fracture specimens (data not shown here). Slip lines and band-like deformation structures can be seen on the surfaces of TM7 and TMM53 specimens, respectively. Fig. 4 shows an EBSD inverse pole figure (IPF) map of the band-like deformation structure observed on the surface of TMM53 specimen and a misorientation profile along the line between points A-A' in the IPF map. As shown in Fig. 4 (b), the misorientation angle between the matrix and the band-like defamation structure is approximately $50.5^{\circ}$, suggesting that $\{332\}<113>$ deformation twinning takes place in TMM53 during the tensile deformation. This implies that the primarily deformation mode of the alloys changes from slip to deformation twinning when Mo is added. Variations in the tensile properties of TM7 and TMM53 are due to the differences in their deformation behavior.

(a)

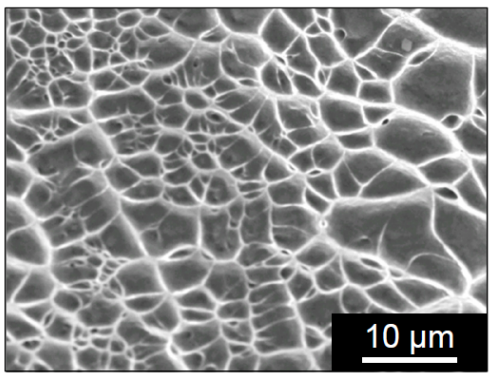

(b)

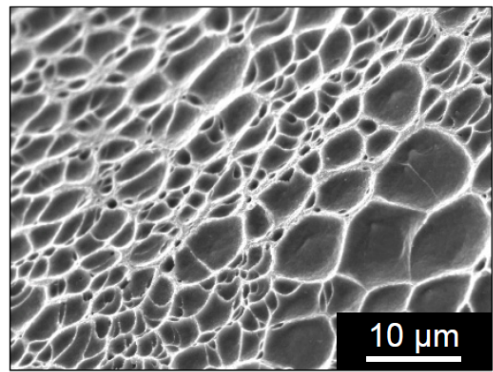

Fig. 3 SEM fractographs of TM7 (a) and TMM53 (b) tensile deformed to fracture. 

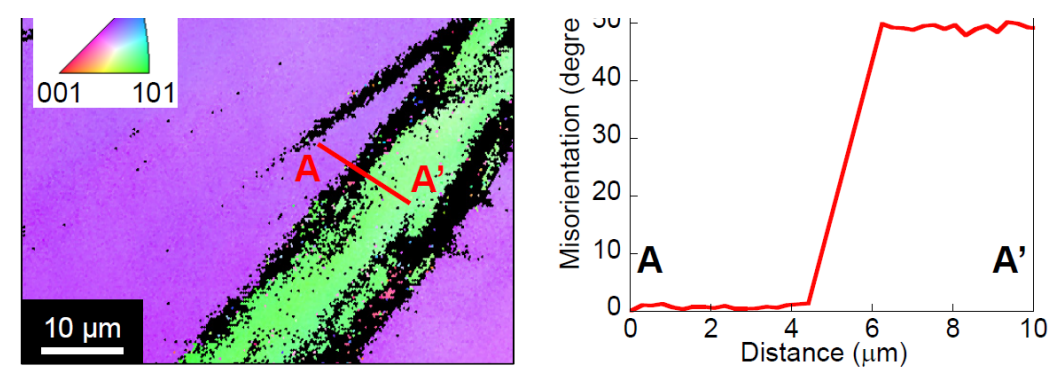

Fig. 4 An IPF map of TMM53 tensile deformed to fracture (a) and misorientation profile along the line between points A-A' in the IPF map (b).

\section{Discussion}

\subsection{Effect of Mo addition on tensile properties and deformation behavior}

As described earlier, both TM7 and TMM53 consist of equiaxed $b$ grains and a nanosized athermal $\omega$ phase. This is because the phase stability of the b matrix for TM7 and TMM53 is the same. However, TM7 and TMM53 exhibit completely different tensile properties, despite these alloys having the same microstructure and $e / a$ (phase stability of the b phase). It should be noted that the difference between yield stress (YS) and UTS for TMM53 is much larger than that for TM7. This means that TMM53 shows a larger work hardening than TM7. Strong work hardening is one of the important features in alloys deformed by $\{332\}<113>$ deformation twinning. Therefore, it is possible to conclude that Mo addition is effective for improving the strength-ductility balance in Ti-Mn alloys via inducing $\{332\}<113>$ deformation twinning.

\subsection{Effect of Mo addition on deformation mode selection}

As shown in Fig. 4, only TMM53 exhibits $\{332\}<113>$ deformation twinning during tensile deformation, indicating that Mo addition can induce the twinning. The selection of the deformation mode is affected by the CRSS for each deformation mode. Thus, the CRSS for $\{332\}<113>$ deformation twinning in TM7 and TMM53 was investigated by a compression test at the [238] orientation using single crystals of these alloys [20]. The CRSS for the twinning in TM7 exceeded 533 $\mathrm{MPa}$, whereas it was $377 \mathrm{MPa}$ for TMM53[20]. This suggests that the CRSS for $\{332\}<113>$ 


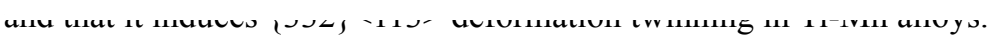

\section{Conclusion}

The effects of Mo addition on the tensile properties and deformation behavior of Ti-Mn alloys were examined in this study with particular focus on $\{332\}<113>$ deformation twinning. The following conclusions could be drawn from the present study:

1. TMM53 exhibits higher tensile strength and larger ductility than TM7 due to its strong work hardening caused by $\{332\}<113>$ deformation twinning.

2. Mo addition is effective in decreasing the CRSS for $\{332\}<113>$ deformation twinning and for inducing twinning in Ti-Mn alloys.

\section{Acknowledgements}

This work was supported in part by Grant-in Aid for Scientific Research (C) (Grant No. 16K06771) from the Japan Society for the Promotion of Science (JSPS), Japan and The light Metal Education Foundation, Japan.

\section{References}

[1] M. Niinomi, Mater. Sci. Eng. A 243 (1998) 231-236.

[2] M. Niinomi, J. Mech. Behav. Biomed. Mater. 1 (2008) 30-42.

[3] J.E.G. Gonzalez, J.C. Mirza-Rosca, J. Electroanal, Chem. 471 (1999) 109-115.

[4] G. He, M. Hagiwara, Mater. Sci. Eng. C 26 (2006) 14-19.

[5] M. Niinomi, M. Nakai, J. Hieda, Acta Biomater. 8 (2012) 3888-3903. 
[6] K. Cho, M. Niinomi, M. Nakai, P.F. Santos, A.M. Liens, M. Ikeda, T. Hattori, Ceramic Transactions, 254 (2015) 1-12.

[7] M. Niinomi, Y. Liu, M. Nakai, H. Liu, H. Li, Regenerative Biomater. 3 (2016) 173-185.

[8] M. Niinomi, T. Hattori, K. Morikawa, T. Kasuga, A. Suzuki, H. Fukui, S. Niwa, Mater. Trans. 43 (2002) 2970-2977.

[9] D. Kuroda, M. Niinomi, M. Morinaga, Y. Kato, T. Yashiro, Mater. Sci. Eng. A 243 (1998) 244249.

[10] T. Akahori, M. Niinomi, H. Fukui, M. Ogawa, H. Toda, Mater. Sci. Eng. C 25 (2005) 248-254.

[11] P. F. Santos, M. Niinomi, K. Cho, M. Nakai, H. Liu, N. Ohtsu, M. Hirano, M. Ikeda, and T. Narushima, Acta Biomater. 26 (2015) 366-376.

[12] K. Cho, M. Niinomi, M. Nakai, H. Liu, P.F. Santos, Y. Itoh, M. Ikeda, M. Abdel-Hady Gepreel, T. Narushima, J. Alloy. Compd. 664 (2016) 272-283.

[13] J.Y. Zhang, J.S. Li, Z. Chen, Q.K. Meng, F. Sun, B.L. Shen, J. Alloy Compd. 699 (2017) 775782.

[14] X.H. Min, K. Tsuzaki, S. Emura, K. Tsuchiya, Materi. Sci. Eng. A 528 (2011) 4569-4578.

[15] A. Ramarolahy, P. Castany, F. Prima, P. Laheurte, I. Péron, T .Gloriant: J. Mech. Behav. Biomed. Mater. 9 (2012) 83-90.

[16] M. Ikeda, M. Ueda, R. Matsunaga, M. Ogawa, M. Niinomi, Mater. Trans. 50 (2009) 2737-2743.

[17] X. Zhou, X. Min, S. Emura, K. Tsuchiya, Materi. Sci. Eng. A 684 (2017) 456-465.

[18] A. Vyskocil, C. Viau, J Appl Toxicol. 19 (1999) 185-192.

[19] S. Hanada, J.Japan Inst.Met.Mater. 25 (1986) 755-764.

[20] R. Morioka, K. Cho, H.Y. Yasuda, Mater. Sci. Forum 941 (2018) 1360-1365. 